\title{
Sagittal balance in the conservative treatment of pathological kyphosis: a retrospective observational study
}

\author{
Salvatore Minnella*, Sabrina Donzelli, Monia Lusini, Fabio Zaina, Michele Romano, Alessandra Negrini, \\ Stefano Negrini
}

From 10th International Conference on Conservative Management of Spinal Deformities - SOSORT 2013

Annual Meeting

Chicago, IL, USA. 8-11 May 2013

\section{Background}

Sagittal alignment of the spine is not well understood. Some authors have demonstrated that the spinal shape is closely correlated with the pelvic shape and orientation. Uncertainty exists if pathological kyphosis should be treated, regardless of sagittal balance.

\section{Purpose}

The goal of this study was to assess how conservative treatment of pathological kyphosis during growth correlates with spinal and pelvic sagittal balance parameters.

\section{Methods}

Study Design: Retrospective observational study. Population: A total of 23 patients ( 15 males; 8 females), aged 11 to 17 years were included. Each patient had at least two clinical evaluations and spinal $\mathrm{X}$ rays (lateral projection) at the time of therapy start (T0) and stop (T1). Methods: 20 patients presented thoracic hyperkyphosis and three presented thoracolumbar kyphosis. All of the patients were treated conservatively; specifically, 17 were treated with brace plus specific exercises and 6 were treated with only specific exercises. For all of the patients we measured the sagittal parameters of thoracic kyphosis (TK), lumbar lordosis (LL), pelvic incidence (PI), pelvic tilt (PT), sacral slope (SS) and spinosacral angle (SSA). Statistical analysis: paired Wilcoxon test and correlation (Pearson).

\section{Results}

Mean and standard deviation for each parameter were

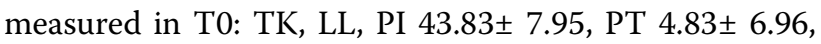

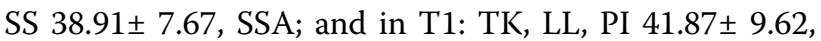
PT $5.48 \pm 7.04$, SS $36.39 \pm 7.80$, SSA. Highly significant improvements were found for the main spinal parameters from T0 to T1: TK reduced from $54.22 \pm 13.58$ to $44.48 \pm$ $12.80(\mathrm{p}=0.0006)$, LL from $57.43 \pm 11.16$ to $51.13 \pm 10.28$ $(\mathrm{p}=0.0077)$ and SSA from $132.87 \pm 9.80$ to $127.09 \pm 9.24$ $(p=0.0036)$; no significant differences were found for the other parameters. Looking at sagittal parameter correlations,very few were found at the start of treatment: SS correlated with LL $(\mathrm{R}=0.651 ; \mathrm{p}=0,007)$, SSA $(\mathrm{R}=0.600$; $\mathrm{p}=0.0025)$ and PI $(\mathrm{R}=0.596 ; \mathrm{p}=0.0027)$ which also correlated with PT $(R=0.515 ; p=0.0119)$. Contrarily, at the end of treatment, most parameters were correlated: LL with PI ( $\mathrm{R}=0.514 ; \mathrm{p}=0.0122)$, SS $(\mathrm{R}=0.499 ; \mathrm{p}=0.0152)$, and SSA ( $R=0.743 ; \mathrm{p}<0.0001)$, PI with $\mathrm{PT}(\mathrm{R}=0.600 ; \mathrm{p}=0.0024)$, SS $(\mathrm{R}=0.691 ; \mathrm{p}=0.0003)$ and SSA $(\mathrm{R}=0.628 ; \mathrm{p}=0.0013)$ and SS with SSA $(\mathrm{R}=0.650 ; \mathrm{p}=0.0008)$.

\section{Conclusions and discussion}

According to our results, conservative treatment is an effective therapy for pathological kyphosis. Since it can change correlations between sagittal balance parameters, making them similar to those described in previous studies in healthy subjects, we can hypothesize its primary role in restoring sagittal balance itself.

Published: 18 September 2013

* Correspondence: Salvatore.minnella@isico.it
ISICO Italian Scientific Spine Institute, Milan, Italy 


\section{References}

1. Roussouly P, Gollogly S, Berthonnaud E, Dimnet J: Classification of the Normal Variation in the Sagittal Alignment of the Human Lumbar Spine and Pelvis in the Standing Position. Spine 2005, 30:346-353.

2. Berthonnaud E, Dimnet J, Roussouly P, Labelle H: Analysis of the Sagittal Balance of the Spine and Pelvis Using Shape and Orientation Parameters. J Spinal Disord Tech 2005, 18:40-47.

3. Vaz G, Roussouly P, Berthonnaud E, Dimnet J: Sagittal morphology and equilibrium of pelvis and spine. Eur Spine J 2002, 11:80-87.

doi:10.1186/1748-7161-8-S2-029

Cite this article as: Minnella et al:. Sagittal balance in the conservative treatment of pathological kyphosis: a retrospective observational study. Scoliosis 2013 8(Suppl 2):O29.

\section{Submit your next manuscript to BioMed Central} and take full advantage of:

- Convenient online submission

- Thorough peer review

- No space constraints or color figure charges

- Immediate publication on acceptance

- Inclusion in PubMed, CAS, Scopus and Google Scholar

- Research which is freely available for redistribution

Submit your manuscript at www.biomedcentral.com/submit 